\title{
Combined operation of SVC, PSS and increasing inertia of machine for power system transient stability enhancement
}

\section{Bablesh Kumar Jha, Ramjee Prasad Gupta, Upendra Prasad}

Electrical Engg. Deptt., B.I.T Sindri, Dhanbad, Jharkhand, India

\section{Email address:}

bableshjha@gmail.com(B. Kumar Jha),Ramjee_gupta@yahoo.com(R. P. Gupta), Upendra_bit@yahoo.co.in (U. Prasad)

\section{To cite this article:}

Bablesh Kumar Jha, Ramjee Prasad Gupta, Upendra Prasad. Combined Operation of SVC, PSS and Increasing Inertia of Machine for Power System Transient Stability Enhancement. American Journal of Electrical Power and Energy Systems.

Vol. 3, No. 1, 2014, pp. 7-14. doi: 10.11648/j.epes.20140301.12

\begin{abstract}
In this paper improvement of transient stability by coordination of PSS (Power System Stabilizer) and SVC (Static var Compensator) and increasing inertia of synchronous machine has been observed. Because single method is not sufficient for improving stability. For this purpose a 9 bus multi machine system has been considered. Transient stability improvement has been tested subjected to three phase fault at bus 3 after 0.5 second and fault has been cleared after 1 second. By the use of PSS, SVC and by increasing inertia method for the test system the electromechanical oscillation for generator electrical power has been reduced and the steady state power transfer has been enhanced. In this paper the Inertia of the machine is not so much increased. Because after increasing inertia of the machine rotor will be havier.so that it is kept always within limit as considering its reliability and economy. And field voltage is also kept limited.
\end{abstract}

Keyword: Transient Stability, ETAP, PSS, Exciter, SVC

\section{Introduction}

Power system stability has been recognized as an important problem for secure system operation. Transient instability has been the dominant stability problem on most systems, and has been the focus of much of the industry's attention concerning system stability. As power systems have evolved through continuing growth in interconnections, use of new technologies and controls, and the increased operation in highly stressed conditions, different forms of system instability have emerged. For example, voltage stability, frequency stability and interarea oscillations have become greater concerns than in the past.

\section{Classification of power system stability}

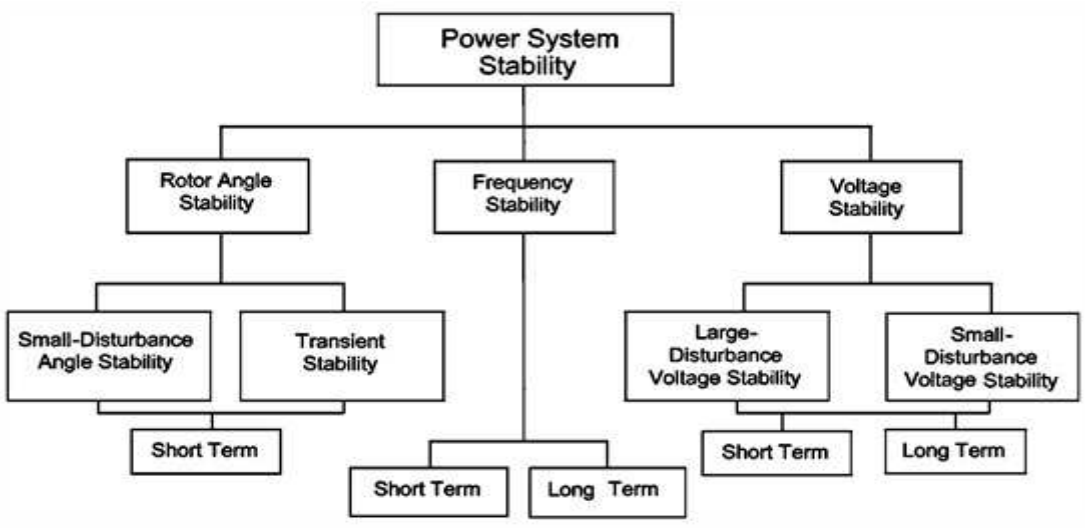

Fig-(1) classification of power system stability [1] 
For convenience of analysis, stability problems are generally divided into two major categories:

- Steady-state stability

- Transient stability

The steady state stability is the stability of the system under conditions of gradual or relatively slow change in load. The load is assumed to be applied at a rate which is slow when compared either with the natural frequency of oscillation of the major parts of the system or with the rate of change of field flux in the rotating machine in response to change in loading.

The transient state stability refers to the maximum flow of power possible through a point without losing the stability with sudden and large changes in the network conditions such as brought about by faults, by sudden large increment of loads.

\subsection{Transient Stability Analysis}

A fault in the system will lead to instability and the machine will fall out of synchronism. If the system can't sustain till the fault is cleared, then the whole system will be in stabilized. During the instability not only the oscillation in rotor angle around the final position goes on increasing but also the change in angular speed. In such a situation the system will never come to its final position. The unbalanced condition or transient condition may leads to instability where the machines in the power system fall out of synchronism.

The system is subjected to a large variety of disturbances. The switching on and off of an appliance in the house is also a disturbance depending upon the size and capability of the interconnected system. Large disturbances such as lightning strokes, loss of transmission line carrying bulk power do occur in the system. Therefore transient stability is defined as the ability of the power system to survive the transition following the large disturbance and to reach an acceptable operating condition.

The physical phenomenon that occurs during a large disturbance is that there will be an imbalance between the mechanical power input and the electrical power output. This will tend to run the generator at high speed. The result will be the loss of synchronism of the generator and the machine will be disconnected from the system. This phenomenon is referred to as a generator going out of step.

The Etap Transient Stability Analysis is designed to investigate the system dynamic response disturbance. The program models dynamic characteristics of a power system, implements the user-defined events and action, solves the system network equation and machine differential equation interactively to find out system and machine response in time domain.

In this paper improvement of transient stability analysis of 9-bus multi machine system by using the coordinated effect of power system stabilizer (PSS), static var compensator (or SVC). In this analysis we create a three phase fault on specified bus and then investigation is to analyze the behavior of the synchronous machine. For this work we used the licensed packaged of ETAP software.

The paper is organized as follows: section 2 gives a brief introduction of power system stabilizer (or PSS) and static var compensator (or SVC) and exciter which has been used. A 9-bus multi machine system or test system is described In section 3. The computer simulation results for system under study are presented and discussed in Section 4 and in Section 5 conclusions are given.

\section{Implementation of SVC and PSS}

Static var compensators are shunt-connected static generator and/or absorbers whose outputs are varied so as to control specific parameters of the electric power system. The term 'static' is used to indicate that SVCs, unlike synchronous compensators, have no moving or rotating main components. By rapidly controlling the voltage and reactive power, an SVC can contribute to the enhancement of the power system dynamic performanance.Normallly, voltage regulation is the primary mode of control, and this improves voltage stability and transient stability. However, the contribution of an SVC to the damping of the system oscillation resulting from voltage regulation alone is usually small; supplementary control is necessary to achieve significant damping.[2]The effectiveness of an SVC in enhancing system stability depends on location of the SVC.).

A commonly used topology of a svc shown in fig.(2).Comprises a parallel combination of TCR and fixed capacitor. It is basically a shunt connected static var generator/absorber. Whose output is adjusted to exchange capacitive or inductive current so as to maintain or control specific parameters of electrical power system, typically bus voltage.

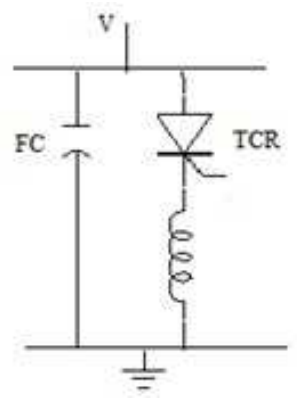

Fig(2) SVC

The reactive power injection of a SVC connected to bus $\mathrm{k}$ is given by

$$
Q_{k}=V_{k}^{2} B_{S V C}
$$

$\mathrm{B}_{\mathrm{svc}}=\mathrm{B}_{\mathrm{c}}-\mathrm{B}_{\mathrm{L}}$; the symbol $\mathrm{B}_{\mathrm{c}}$ and $\mathrm{B}_{\mathrm{L}}$ are the respective susceptance of the fixed capacitor and TCR.it is also important to note that a svc does not exchange real power with the system. 
The small signal dynamic model of a SVC is shown in fig.(3). $\Delta \mathrm{B}_{\text {svc }}$ is defined as $\Delta \mathrm{B}_{\mathrm{c}}-\Delta \mathrm{B}_{\mathrm{L}}$.the differential equation

from this block diagram can easily be defined as

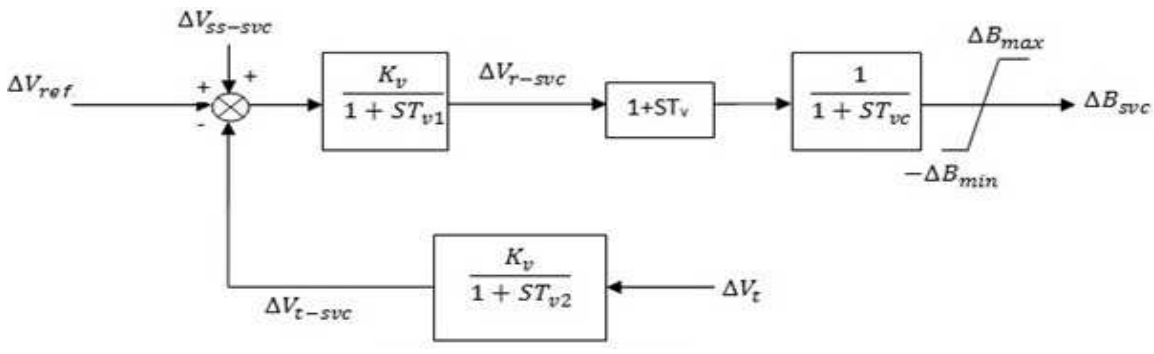

Fig(3) SVC Dynamic model

$$
\begin{gathered}
\frac{d}{d t} \Delta B_{s v c}=\frac{1}{T_{s v c}}\left\{-\Delta B_{s v c}+\left(1-\frac{T_{v 1}}{T_{v 2}}\right) \Delta V_{r-s v c}-\frac{K_{v} T_{v 1}}{T_{v 2}} \Delta V_{t-s v c}\right\}+\frac{K_{v} T_{v 1}}{T_{v 2} T_{s v c}}\left\{\Delta V_{s s-s v c}+\Delta V_{r e f .}\right\} \\
\frac{d}{d t} \Delta V_{r-s v}=\frac{1}{T_{v 2}}\left\{-\Delta V_{r-s v c}-K_{v} \Delta V_{t-s v c}+K_{v} V_{r e f .}+K_{v} V_{s s-s v c}\right\} \\
\frac{d}{d t} \Delta V_{t-s v c}=\frac{1}{T_{m}}\left\{\Delta V_{t}-\Delta V_{t-s v c}\right\}
\end{gathered}
$$

$K_{v}, T_{v 1}, T_{v 2}$ are the gain and time constant of voltage controller respectively. $\mathrm{T}_{\mathrm{svc}}$ is the time constant associated with $\mathrm{SVC}$ response. $\mathrm{T}_{\mathrm{m}}$ is the voltage sensing circuit time constant.

Svc control model which has been used is shown above in fig.(3).An SVC comprising a fixed capacitor and a thyristor-controlled reactor is considered for enhancement of the system stability.

\subsection{Power System Stabilizer}

The basic of a power system stabilizer (PSS) is to add damping to the generator oscillation by using auxiliary stabilizing signal(s).To provide damping, the stabilizer must produce a component of electrical torque in phase with the rotor speed variation. This is achieved by modulating the generator excitation so as to develop a component of electrical torque in phase with rotor speed deviation. Shaft speed, integral of power and terminal frequency are among the commonly used input signals to PSS.[3].PSS based on shaft speed signal has been used successfully since the mid-1960s.a technique developed to derive a stabilizing signal from measurement of shaft speed of a system. Among the important consideration in the design of equipment for the measurement of speed deviation is the minimization of noise caused by shaft run out and other causes.[3-4]the allowable level of noise is dependent on its frequency. For noise frequency below $5 \mathrm{~Hz}$, the level must be less than $0.02 \%$, since significant changes in terminal voltage can be produced by low-frequency changes in the field voltage. The application of shaft speed stabilizer to thermal unit requires a careful consideration of the effects on torsional oscillation. The stabilizer, while damping the rotor oscillation, can cause instability of the torsional modes. One approach successfully used to circumvent the problem is to sense the speed at a location on the shaft near the nodes of the critical torsional modes [5-6].In addition , an electronic filter is used in stabilizing path to attenuate the torsional components.

Power system stabilizer which has been used in this research is shown below in fig.(4).

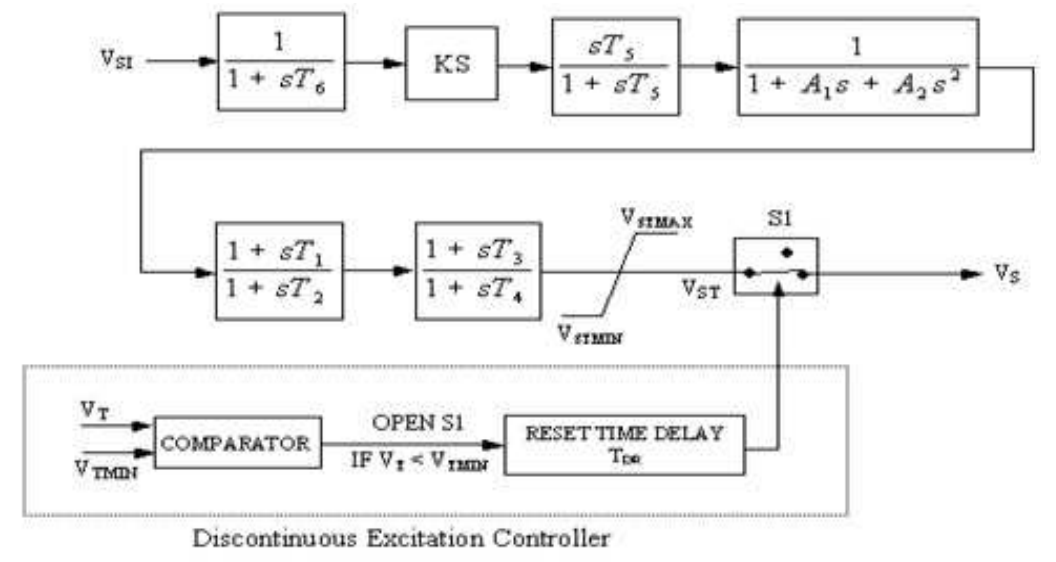

Fig.-(4) IEEE Type-1 PSS(PSSIA) 


\subsection{Exciter}

The IEEE type of DC1 exciter is field-controlled dc commutator exciters, with continuously acting voltage regulators. The exciter may be separately excited or self exicted, the latter type being more common. When selfexcited, $\mathrm{Ke}$ is selected so that initially $\mathrm{Vr}=0$, representing operator action of tracking the voltage regulator by periodically trimming the shunt field rheostat set point.[7]

\section{Model System}

The test system that has been considered here is the 9Bus Multi-Machine System as shown below in Fig.(5).

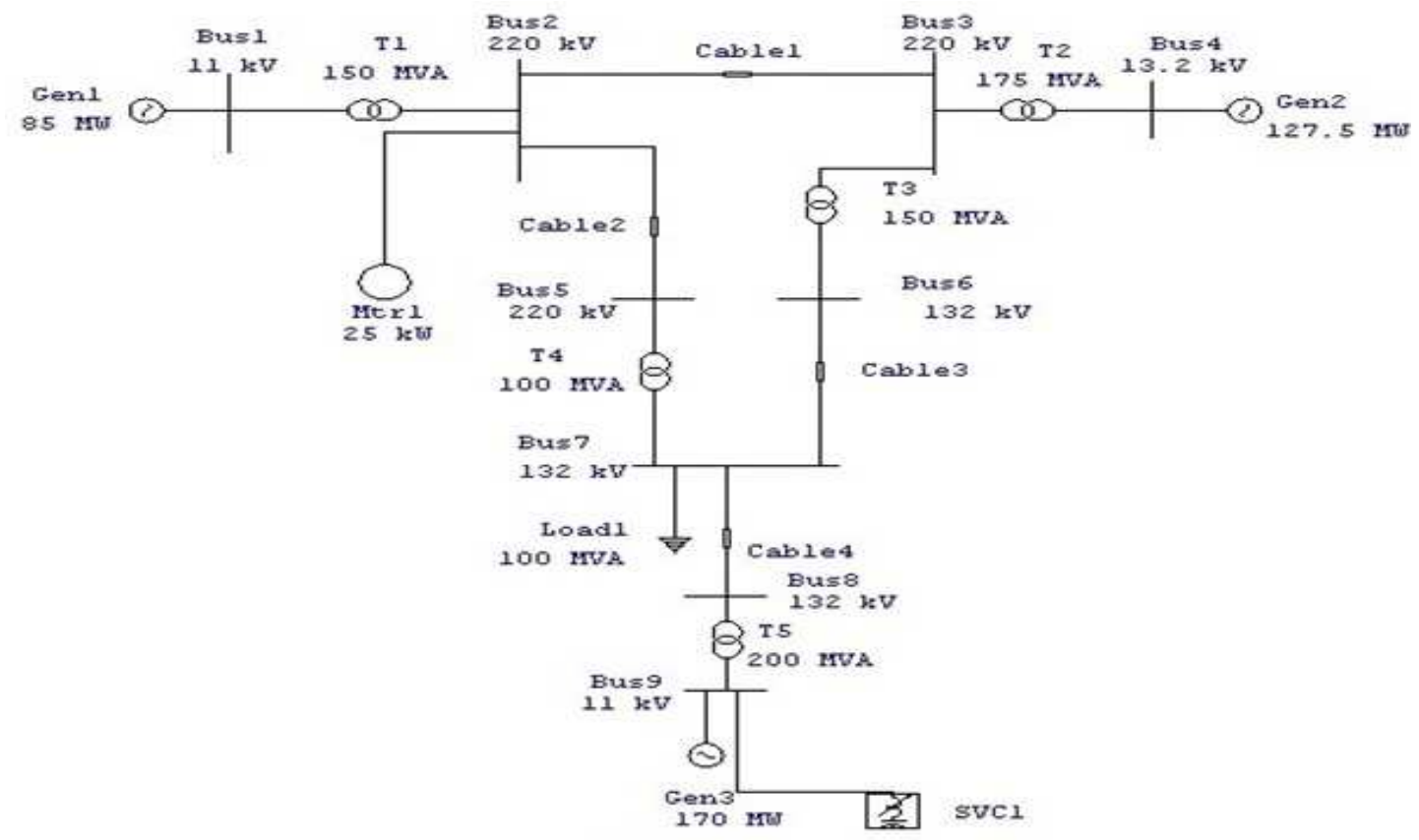

Fig.(5) test system

Which consisted 9-bus, three generators, four cables, five transformers and two loads one is static load of 100 MVA and another is an induction motor of $25 \mathrm{MW}$. Gen-1,
Gen-2 and Gen-3 rated of $85 \mathrm{MW}, 127.5 \mathrm{MW}$ and $170 \mathrm{MW}$ respectively. All other input parameters of generators are shown below in Table-1,2 and 3.

Table-1 Synchronous machine parameters

\begin{tabular}{ccccccccccccccccc}
\hline & \multicolumn{1}{c}{ Machine } & \multicolumn{3}{c}{ Rating } & \multicolumn{4}{c}{ Positive sequence impedence(\%) } & \multicolumn{4}{c}{ Zero seq. Z(\%) } \\
\hline ID & TYPE & MODEL & MVA & KV & $\mathrm{R}_{\mathrm{a}}$ & $\mathrm{X}_{\mathrm{d}}{ }^{\prime}$ & $\mathrm{X}_{\mathrm{d}}{ }^{\prime}$ & $\mathrm{X}_{\mathrm{d}}$ & $\mathrm{X}_{\mathrm{q}}{ }^{\prime \prime}$ & $\mathrm{X}_{\mathrm{q}}{ }^{\prime}$ & $\mathrm{X}_{\mathrm{q}}$ & $\mathrm{X}_{1}$ & $\mathrm{X}_{\mathrm{R}}$ & $\mathrm{R}_{0}$ & $\mathrm{X}_{0}$ \\
\hline Gen1 & Generator & $\begin{array}{l}\text { Subtransient, } \\
\text { Round-Rotor }\end{array}$ & 100 & 11 & 1 & 19 & 28 & 155 & 19 & 65 & 155 & 15 & 7 & 1 & 7 \\
Gen2 & Generator & $\begin{array}{l}\text { Subtransient, } \\
\text { Round-Rotor }\end{array}$ & 150 & 13.2 & 1 & 19 & 28 & 155 & 19 & 65 & 155 & 15 & 7 & 1 & 7 \\
Gen3 & Generator & $\begin{array}{l}\text { Subtransient, } \\
\text { Round-Rotor }\end{array}$ & 200 & 11 & 1 & 19 & 28 & 155 & 19 & 65 & 155 & 15 & 7 & 1 & 7 \\
\hline
\end{tabular}

Table-2 Dynamic Pparameters Of Synchronous Machine

\begin{tabular}{|c|c|c|c|c|c|c|c|c|c|c|c|c|}
\hline \multirow{2}{*}{$\begin{array}{c}\text { Machine } \\
\text { ID }\end{array}$} & \multirow{2}{*}{$\begin{array}{c}\text { Connected bus } \\
\text { ID }\end{array}$} & \multicolumn{4}{|c|}{ Time cons.(sec.) } & \multicolumn{5}{|c|}{$\mathrm{H}(\mathrm{Sec}),. \mathrm{D}(\mathrm{MW} \mathrm{pu} / \mathrm{Hz}) \&$ Saturation } & \multicolumn{2}{|c|}{ Grounding } \\
\hline & & $\mathrm{T}_{\mathrm{d} 0} "$ & $\mathrm{~T}_{\mathrm{d} 0}$ & $\mathrm{~T}_{\mathrm{q} 0}$, & $\mathrm{T}_{\mathrm{q} 0}$ & $\mathrm{H}$ & $\% \mathrm{D}$ & S100 & S120 & Sbreak & Conn. & Type \\
\hline Gen1 & Bus1 & 0.03 & 6.5 & 0.03 & 1.25 & 12 & 0 & 1.7 & 1.18 & 0.8 & WYE & SOLID \\
\hline Gen2 & Bus4 & 0.03 & 6.5 & 0.03 & 1.25 & 12 & 0 & 1.7 & 1.18 & 0.8 & WYE & SOLID \\
\hline Gen3 & Bus9 & 0.03 & 6.5 & 0.03 & 1.25 & 12 & 0 & 1.7 & 1.18 & 0.8 & WYE & SOLID \\
\hline
\end{tabular}


Table-3 Mechanical parameters of synchronous machine

\begin{tabular}{|c|c|c|c|c|c|c|c|c|c|c|c|c|c|}
\hline \multicolumn{2}{|c|}{ Machine } & \multicolumn{3}{|c|}{ Generator/Motor } & \multicolumn{3}{|c|}{ Coupling } & \multicolumn{3}{|c|}{ Prime Mover/Load } & \multicolumn{3}{|c|}{ Equivalent Total } \\
\hline ID & TYPE & $\mathrm{WR}^{2}$ & RPM & $\mathrm{H}$ & $\mathrm{WR}^{2}$ & RPM & $\mathrm{H}$ & $\mathrm{WR}^{2}$ & RPM & $\mathrm{H}$ & $\mathrm{WR}^{2}$ & RPM & $\mathrm{H}$ \\
\hline Gen 1 & Gen. & 32406 & 1500 & 4 & 32406 & 1500 & 4 & 32406 & 1500 & 4 & 97217.99 & 1500 & 12 \\
\hline Gen2 & Gen. & 48609 & 1500 & 4 & 48609 & 1500 & 4 & 48609 & 1500 & 4 & 145826.98 & 1500 & 12 \\
\hline Gen3 & Gen. & 64811 & 1500 & 4 & 64811 & 1500 & 4 & 64811 & 1500 & 4 & 194432.98 & 1500 & 12 \\
\hline
\end{tabular}

$\mathrm{WR}^{2}: \mathrm{kg}-\mathrm{m}^{2} \quad \mathrm{H}: \mathrm{MW}-\mathrm{Sec} / \mathrm{MVA}$

The IEEE type of DC1 exciter, with continuously acting voltage regulators is installed with all generators. The exciter is self-excited. When self-excited, $\mathrm{Ke}$ is selected so that initially $\mathrm{Vr}=0$, representing operator action of tracking the voltage regulator by periodically trimming the shunt field rheostat set point. Input data of exciter is shown below in Table-4.

Table-4 Power system stabilizer (pss) input data

type: pss 1 a

\begin{tabular}{ccccccccccccccc}
\hline Generator ID & VSI & KS & VSTMax & VSTMin & VTMin & TDR & A1 & A2 & T1 & T2 & T3 & T4 & T5 & T6 \\
\hline Gen1 & SPEED & 3.15 & 0.9 & -0.9 & 0 & 0.2 & 0 & 0 & 0.76 & 0.1 & 0.76 & 0.1 & 1 & 0.1 \\
Gen2 & SPEED & 3.15 & 0.9 & -0.9 & 0 & 0.2 & 0 & 0 & 0.76 & 0.1 & 0.76 & 0.1 & 1 & 0.1 \\
Gen3 & SPEED & 3.15 & 0.9 & -0.9 & 0 & 0.2 & 0 & 0 & 0.76 & 0.1 & 0.76 & 0.1 & 1 & 0.1 \\
\hline
\end{tabular}

An IEEE type of PSS1A is connected with all generators. The parameter of power system stabilizer is shown in Table-5.

Table-5 Exciter input data type: $d c 1$

\begin{tabular}{|c|c|c|c|c|c|c|c|c|c|c|c|c|c|c|}
\hline $\begin{array}{l}\text { Machine } \\
\text { ID }\end{array}$ & $\begin{array}{l}\text { Control } \\
\text { Bus ID }\end{array}$ & $\begin{array}{c}\mathrm{KA} \\
\mathrm{Efd}_{\max }\end{array}$ & $\mathrm{KE}$ & $\mathrm{KF}$ & $\mathrm{TA}$ & TB & $\mathrm{TC}$ & $\mathrm{TE}$ & $\mathrm{TF}$ & TR & $\mathrm{VR}_{\max }$ & $\mathrm{VR}_{\text {min }}$ & $\mathrm{SE}_{\max }$ & SE.75 \\
\hline Gen1 & Bus1 & $\begin{array}{c}46 \\
2.63\end{array}$ & 0.05 & 0.1 & 0.06 & 0 & 0 & 046 & 1 & 0.005 & 1 & -0.9 & 0.33 & 0.1 \\
\hline Gen2 & Bus4 & $\begin{array}{c}46 \\
2.63\end{array}$ & 0.05 & 0.1 & 0.06 & 0 & 0 & 0.46 & 1 & 0.005 & 1 & -0.9 & 0.33 & 0.1 \\
\hline Gen3 & Bus9 & $\begin{array}{c}46 \\
2.63\end{array}$ & 0.05 & 0.1 & 0.06 & 0 & 0 & 0.46 & 1 & 0.005 & 1 & -0.9 & 0.33 & 0.1 \\
\hline
\end{tabular}

The rating of the SVC is assumed to be 200 Mvar capacitive and 200Mvar inductive .The voltage regulator gain is set at 10 to provide a $10 \%$ slope in the control range.

\section{Simulation Result and Discussion}

The Etap Transient Stability Analysis is designed to investigate the system dynamic response disturbance. The program models dynamic characteristics of a power system, implements the user-defined events and action, solves the system network equation and machine differential equation interactively to find out system and machine response in time domain.

In this paper we discuss the transient stability performance with PSS, SVC and by increasing inertia of synchronous machine. The transient stability improvement is not only sufficient by using one method. So here we use these three combined method for improving stability. Here we use ACCELERATED GAUSS-SEIDEL for initial load flow calculation. In which maximum number of iteration is
2000 and Solution Precision for the Initial LF is 0.000001 And Time Increment for Integration Steps $(\Delta t)$ is 0.0100 and acceleration factor for the initial load flow is 1.45.Intial inertia of the installed machine was $4 \mathrm{MW}-\mathrm{Sec} / \mathrm{MVA}$ and after increasing its inertia is $7 \mathrm{MW}-\mathrm{Sec} / \mathrm{MVA}$.Inertia of the machine is not so much increased. Because after increasing inertia of the machine rotor will be havier.so that it is kept always within limit as considering its reliability and economy.. The electromechanical oscillation for generator electrical power is reduced as well as the steady state power is also enhanced as seen in fig-(6).oscillation in terminal current and field current is also reduced and the magnitude of field current is also reduced as seen in Fig(7) \&Fig.(9).Field voltage of Gen-1 is initially oscillated but after some time it is constant and within limit as shown in fig.(8).if only inertia of generator is increased then field voltage was does not change.

The different plot for Gen-1. When a three phase fault on bus-3 at $0.5 \mathrm{sec}$ and cleared at $1 \mathrm{sec}$ are shown below in fig. 


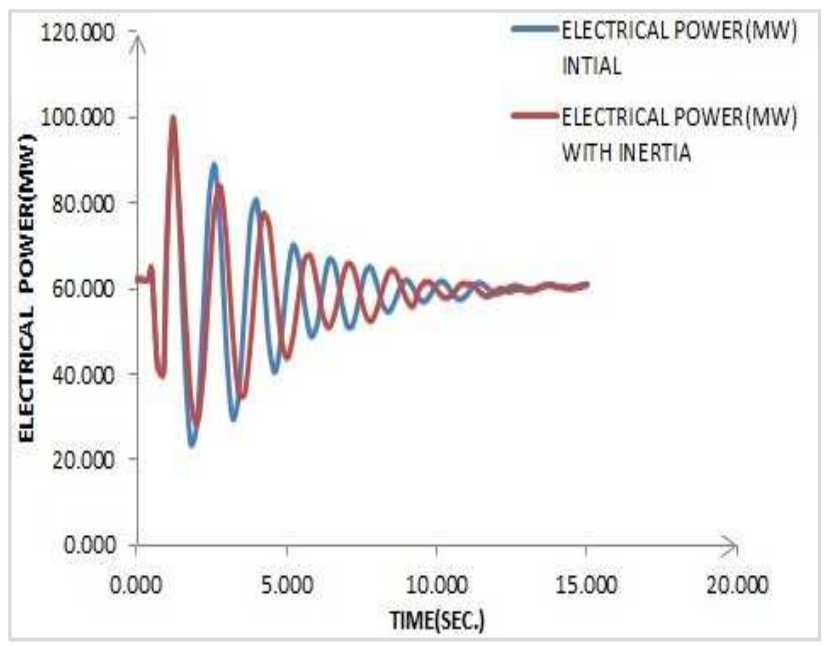

(1)

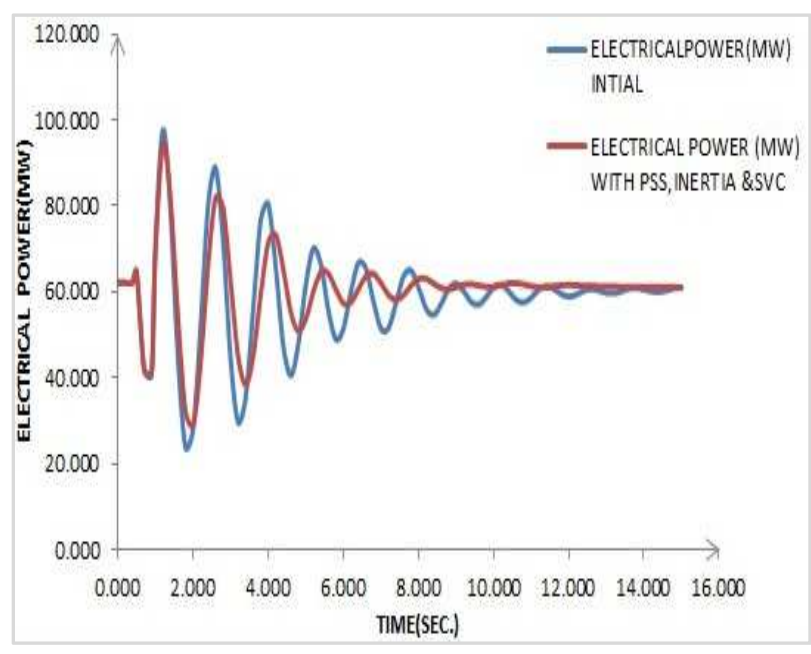

(2)

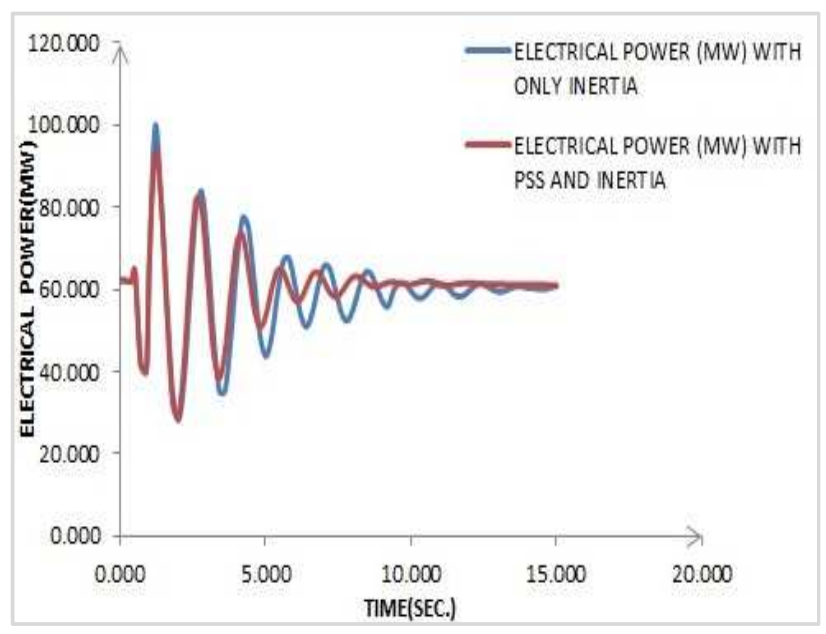

(3)

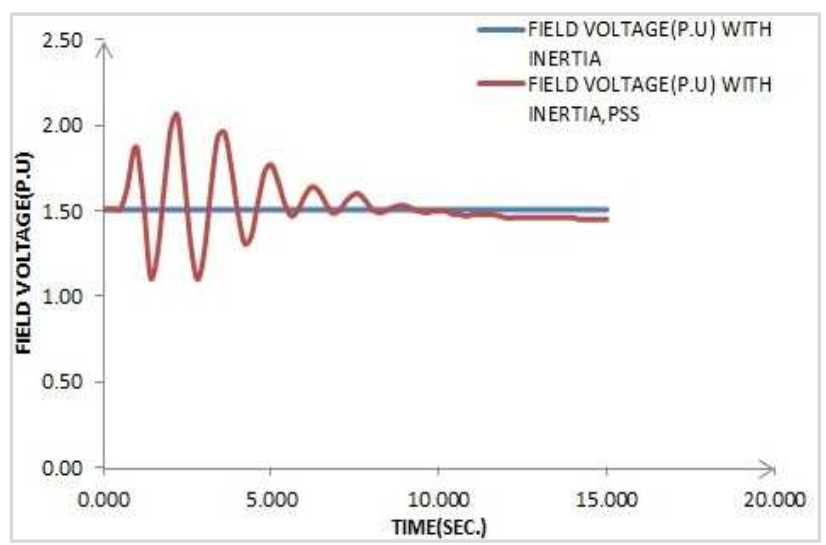

(1)

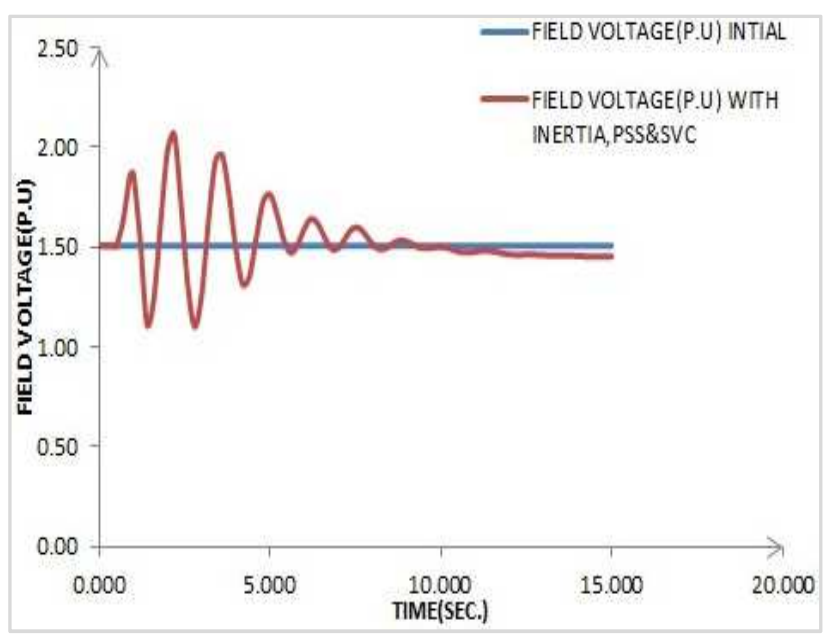

(2)

Fig(7) Field voltage of Gen-1 (1)implementation of inertia\&pss (2)implementation of inertia,pss and svc.

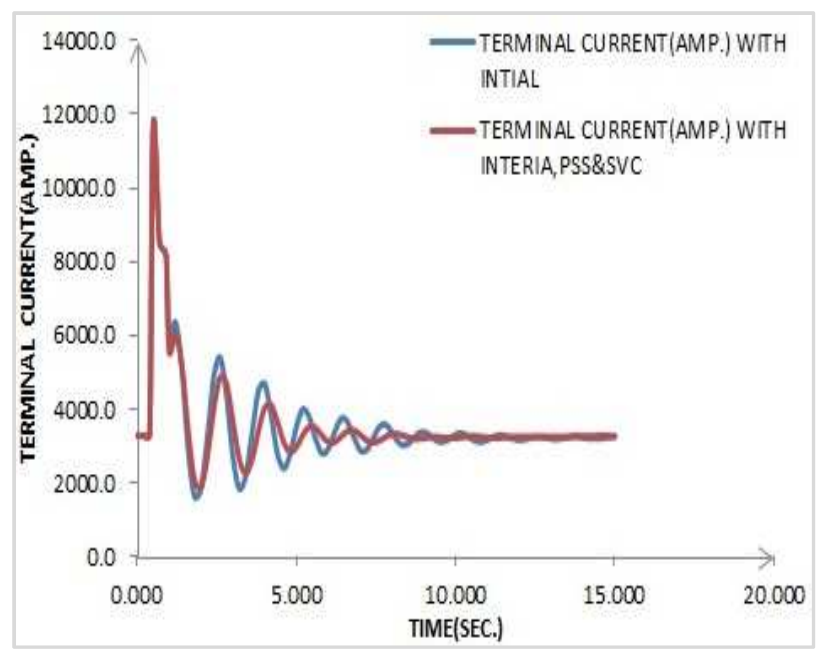

(1)

Fig(6) Electrical power of Gen-1 (1)only inertia is increased (2) implementation of pss and inertia (3) implementation of inertia ,pss\&svc. 


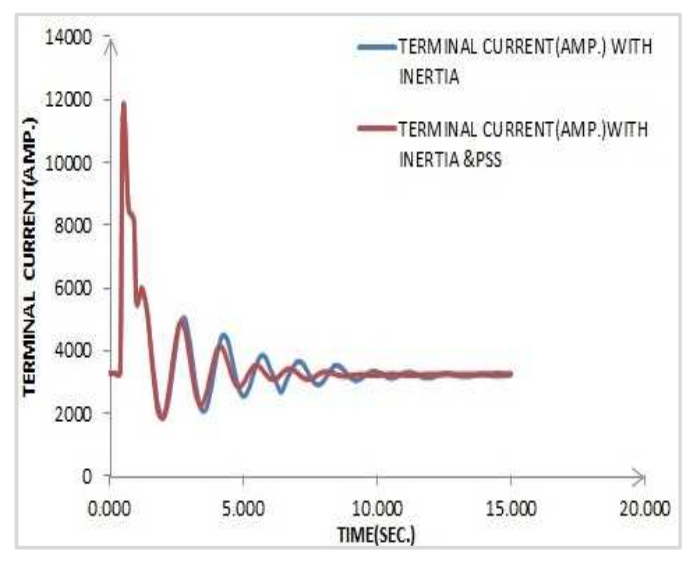

(2)

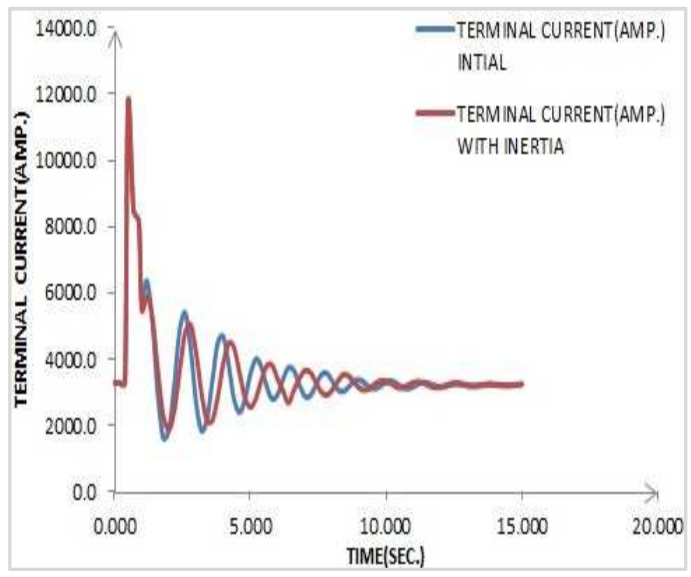

(3)

Fig(8) terminal current of Gen-1 (1)only inertia is increased (2) implementation of inertia \&svc (3) implementation of inertia,pss\&svc.

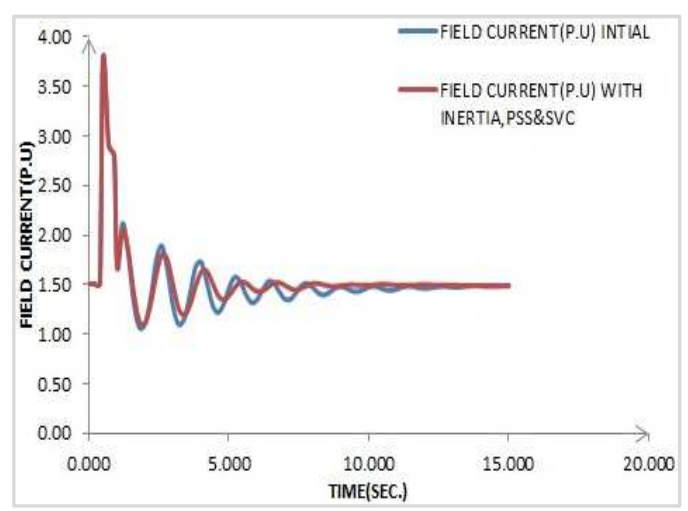

(1)

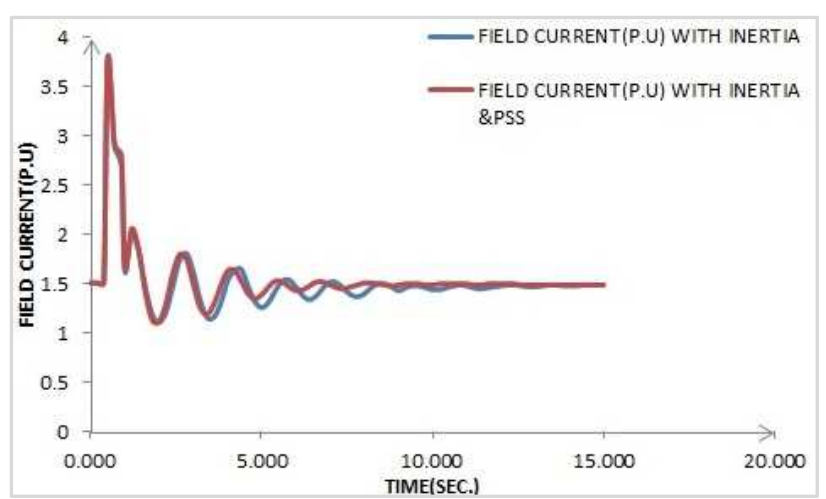

(2)

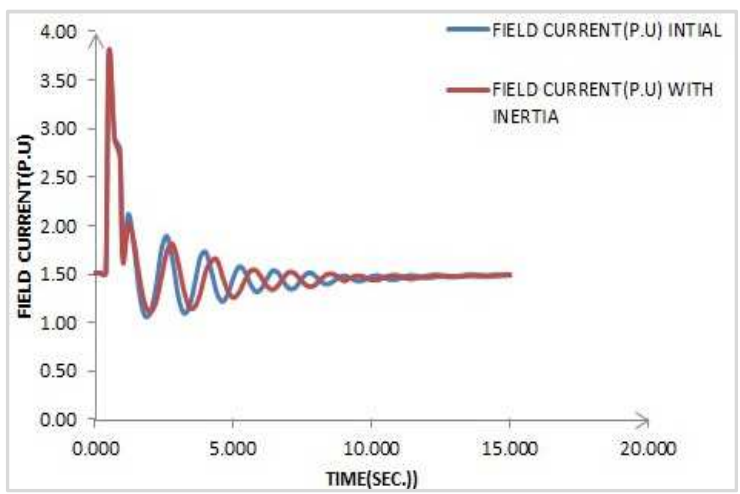

(3)

Fig(9)Field current of Gen-1 (1)only inertia is increased (2) implementation of inertia and pss (3) implementation of inertia ,pss\&svc.

\section{Conclusion}

In this paper a new optimal control approaches for improvement of transient stability. Here Transient stability Performances of the multi machine system by using coordinated effect of PSS, SVC and by increasing inertia of machine and conventional method has been compared. And we see that better response in terms of electromechanical oscillation has been achieved in case of with PSS and SVC.The proposed method also has the advantage of considering the permissible system conditions. In general, analytical analysis and simulation results using E-TAP software show that the proposed and good flexibility for transient stability improvement.

\section{Nomenclature}

\begin{tabular}{|c|c|c|c|}
\hline Parameter & Defintion & Parameter & Definition \\
\hline $\mathrm{Ra}$ & armature resistance in ohm & Xd", Xq" & $\begin{array}{l}\text { direct-axis,quadrature-axis synchronous subtransient } \\
\text { reactance in percent }\end{array}$ \\
\hline $\mathrm{Xd}, \mathrm{Xq}$ & $\begin{array}{l}\text { direct-axis,quadrature-axis synchronous transient } \\
\text { reactance in percent }\end{array}$ & $\mathrm{Xd}, \mathrm{Xq}$ & $\begin{array}{l}\text { direct-axis,quadrature-axis synchronous reactance in } \\
\text { percent }\end{array}$ \\
\hline $\mathrm{X} 1$ & positive sequence reactance & $\mathrm{R} 0, \mathrm{X} 0$ & zero sequence resistance.reactance \\
\hline $\mathrm{X} / \mathrm{R}$ & armature $X / R$ ratio & Td0",Tq" & $\begin{array}{l}\text { direct-axis,quadrature-axis subtransient open circuit time } \\
\text { constant in seconds }\end{array}$ \\
\hline
\end{tabular}




\begin{tabular}{|c|c|c|c|}
\hline $\mathrm{Td} 0^{\prime}, \mathrm{Tq}^{\prime}$ & $\begin{array}{l}\text { direct-axis,quqdrature-axis transient open-circuit } \\
\text { time constant in seconds }\end{array}$ & $\mathrm{H}$ & intertia of synchronous machine \\
\hline $\mathrm{D}$ & shaft mechanical damping term in percent & $\mathrm{S} 100, \mathrm{~S} 120$ & saturation factor at $100 \%, 120 \%$ terminal voltage \\
\hline Sbreak & $\begin{array}{l}\text { per unit of terminal voltage at which the generator } \\
\text { saturation curve skews from the air-gap line. }\end{array}$ & VSI & PSS input (speed, power or frequency) in pu \\
\hline KS & PSS gain(p.u) & $\begin{array}{l}\text { VSTmax, } \\
\text { VSTmin }\end{array}$ & Maximum, Minimum PSS output(p.u) \\
\hline TDR & Reset time delay for discontinuous controller(sec.) & $\mathrm{A} 1, \mathrm{~A} 2$ & PSS signal conditioning frequency filter constant(p.u) \\
\hline $\mathrm{T} 1, \mathrm{~T} 3$ & PSS lead compensation time constant(sec.) & $\mathrm{T} 2, \mathrm{~T} 4$ & PSS leg compensation time constant(sec.) \\
\hline $\mathrm{T} 5, \mathrm{~T} 6$ & PSS washout time constant(sec & KA & Regulator gain(p.u) \\
\hline Efdmax & Maximum exciter output voltage(p.u) & $\mathrm{KE}$ & Exciter constant for self-excited field(p.u) \\
\hline Kf & Regulator stabilizing circuit gain(p.u) & TA & Regulator amplifier time constant(sec.) \\
\hline $\mathrm{TB}, \mathrm{TC}$ & Voltage regulator time constant(sec.) & $\mathrm{TE}$ & Exciter time constant(sec.) \\
\hline $\mathrm{TF}$, & $\begin{array}{l}\text { Regulator stabilizing circuit,Input filter time } \\
\text { constant(sec.) }\end{array}$ & TR & Regulator Input filter time constant(sec.) \\
\hline VRmax, & Maximum value of the regulator output voltage(p.u) & VRmin & Minimum value of the regulator output voltage(p.u) \\
\hline SEmax & The value of excitation function at Efdmax & SE.75 & The value of excitation function at 0.75 Efdmax \\
\hline K & Voltage regulator gain(p.u) & $\mathrm{a} 1, \mathrm{a} 2$ & Additional control signal gain \\
\hline $\mathrm{T}$ & Voltage regulator time constant(sec.) & $\mathrm{tm}$ & Measurement time constant(sec.) \\
\hline $\mathrm{Tb}$ & Thyristor phase control time constant(sec.) & $\mathrm{td}$ & Thyristor phase control delay(sec.) \\
\hline $\mathrm{t} 1, \mathrm{t} 2$ & Voltage regulator time constant(sec.) & tbmax,tbmin & Maximum,minimumsusceptance limit(p.u) \\
\hline
\end{tabular}

\section{References}

[1] P.L. Dandeno, A.N Karas, K.R. McClymont, and W.Watson,"Effect of High-Speed Rectifier Exication System on Generator Stability Limits," IEEE Trans.,vol. PAS-87,pp.190-201,January 1968

[2] W.Watson and G.Manchur, "Experience with supplementary Damping Signals for Generator Static ExicationSystem,'IEEE Trans.,Vol.PAS-92,pp. 199203,January/February 1973

[3] W.Watson and M.E Coultes ,'Static Exicter Stabilizing Signals on Large Generators-Mechanical Problems,"IEEE Trans.,Vol. PAS-92,pp.204-211,January/February 1973

[4] P.Kundur ,D.C.Lee and H.M. Zein EL-Din,"Power system stabilizer fot thermal units:Analytical Techniques and OnSite Validation,'IEEE Trans.,Vol.PAS-100,pp. 8195,January 1981

[5] M.L. Shelton, R.F Winklemen, W.A Mittelstandt, and W.L Bellerby,"Bonneville Power Administration 1400 MW Braking Resistor,'IEEE Trans.,VOL.PAS-94,pp.602611,March/april 1975

[6] P.K. Iyambo, R. Tzonova, "Transient Stability Analysis of the IEEE 14-Bus Electrical Power System", IEEE Conf. 2007

[7] N. Mo, Z.Y. Zou, K.W. Chan, T.Y.G. Pong, "Transient stability constrained optimal power flow using particleswarm optimization", IET Generation, Transmission \& Distribution, Vol. 1, pp. 476-483, 2007

[8] D. Chatterjee, A. Ghosh, "Transient Stability Assessment of PowerSystems Containing Series and Shunt Compensators," IEEE Trans. onpower systems, vol. 22, no. 3, August 2007

[9] IEEJ Technical Committee, Standard models of power system, IEEJ Technical Report, Vol. 754, 1999

[10] P. M. Anderson and A. A. Fouad. Power System Control and Stability.The IEEE Press, 1995.

[11] M. H. Haque, "Evaluation of First Swing Stabilityof a Large Power System With Various FACTS Devices”,IEEE Trans. Power Systems, vol.23, no.3,pp.1144-1151, August 2008

[12] P.Kundur,"effective use of power system stabilizer for enhancement of power system stability."in proc. 1999.IEEE PES Power engg. Society Summer meeting pp. 96-103

[13] G.K morison ,B.Gao and P.kundur,"volatage stability analysis using static and dynamic approaches,"IEEE Trans. Power system ,vol.8,pp. 1159-1171, aug.1993

[14] LerchE,PovhDAdvancedSVCcontrolfordampingpower system oscillations. IEEE Trans Power Syst 16(2)pp.:524$535,(1991)$ 